\title{
Is clumsiness a marker for Asperger syndrome?
}

\author{
M. GHAZIUDDIN, E. BUTLER, L. TSAI \& N. GHAZIUDDIN \\ University of Michigan, Ann Arbor, Michigan, USA
}

\begin{abstract}
Although Asperger syndrome (AS) has been included in the ICD-10 as a distinct category within the pervasive developmental disorders, it is still unclear to what extent it differs from normal-intelligence autism (highfunctioning autism; HFA). Persons with AS are said to be particularly clumsy. To test the hypothesis that clumsiness can reliably distinguish AS from autism, the present authors compared 11 patients with AS (ICD-10; 10 males; mean age, 13.6 years; mean IQ 98) with nine patients with HFA (ICD-10/DSMIII-R; eight males; mean age, $12 \cdot 9$ years; mean IQ, 84). Clumsiness was assessed by the Bruininks-Oseretsky test. Both groups showed problems with coordination and the distribution of standard scores was virtually identical. This suggests that motor clumsiness, as measured by tests of coordination, may not reliably distinguish AS from HFA. However, qualitative differences may occur between the two groups in the manner in which movements are performed. Further research with larger samples may elicit differences into the pattern of motor deficits that occur in autism and AS.
\end{abstract}

\section{INTRODUCTION}

Asperger syndrome (AS) is a pervasive developmental disorder characterized by social deficits in the presence of normal language and cognitive development. Although it was first described by Hans Asperger about half a century ago (Asperger 1944), it has only now been included in the ICD-10 as a distinct category within the pervasive developmental disorders (WHO 1988). However, its nosological status remains unclear. Some authorities believe that it is a distinct diagnostic entity, while others have suggested that the label of AS should not be used until an empirically based distinction from high-functioning autism (HFA) can be demonstrated (Schopler 1985).

Apart from clarifying the subtypes of autistic disorders, establishing the diagnostic validity of AS is important for a variety of other reasons. For example, it has been claimed that AS may be associated with increased psychiatric morbidity (Wing 1981), especially with mood disorders (Gillberg 1985; DeLong \& Dwyer 1988). Also, AS may have an overlap with schizoid/schizotypal personality disorder (Wolff \& Barlow 1979) and with non-verbal learning disability (Stevens \& Moffit 1988).

One possible reason for the controversy surrounding this syndrome is the lack of consensus about its clinical features. It is generally accepted that the core features

Correspondence: Dr Mohammad Ghaziuddin, Psych Annex Box 0290, University of Michigan Medical Center, 200 East Hospital Drive, Ann Arbor, MI, USA. 
consist of social isolation, odd and pedantic speech, poor nonverbal communication, and preoccupation with certain idiosyncratic interests. Although a variety of diagnostic criteria have been proposed for this disorder (Ghaziuddin et al. 1992a), according to the ICD-10, a person with AS suffers from autistic social dysfunction in the presence of normal intelligence and normal language development (see 'Appendix').

In addition, clumsiness has been proposed as a diagnostic feature of this syndrome. Wing (1981) suggested that gross motor movements of patients with AS are clumsy and ill-coordinated. In a subsequent paper (Burgoine \& Wing 1983), she argued that 'clumsy and ill-coordinated movements and odd posture' form one of the major clinical features of this syndrome. Tantam (1988a) also suggested that the diagnosis of AS should be used for those autistic children who 'use language freely but fail to make adjustment to fit different social contexts or the needs of different listeners, wish to be sociable but fail to make relationships with peers, develop idiosyncratic but engrossing interests, have marked impairments of nonverbal expressiveness and are conspicuously clumsy' (italics added). The ICD-10 also mentions clumsiness as a usual feature of this syndrome, with the caveat that it is not essential for diagnosis (WHO 1988).

Despite the proposed association, few studies have systematically assessed the presence of clumsiness in AS. In a review of over 40 publications on AS, Ghaziuddin et al. (1992b) could identify no more than four studies which specifically assessed and measured clumsiness. In a study of 23 children aged 5-18 years with AS, Gillberg (1989) found significantly more clumsiness in AS than HFA. Clumsiness was diagnosed as a score on the gross motor subscale of Griffith's scale of 15 points or more below the child's IQ level. In Tantam's studies (Tantam 1988b, c), subjects were timed while attempting to stand on one leg with their eyes closed and were also required to catch a paper ball which was thrown to them. In the remaining study (Szatmari et al. 1989), patients were asked to perform five tasks; namely, ability to dress, tie shoe-laces, eat with utensils, use pencils and do puzzles.

Quite often, the presence of clumsiness in AS has been defined on the basis of the clinician's subjective impression. Most studies have not used standardized tests of clumsiness, such as the Test of Motor Impairment (Stott et al. 1984) or those developed by Gubbay (1975). In some instances, the diagnosis of clumsiness has apparently been made on the basis of IQ tests, although these tests are not standardized for measuring clumsiness. In addition, often no attempt has been made to differentiate between clumsiness in the upper limbs from that in the lower limbs, or to take the effect of age into account. Thus, despite the increasing interest in this symptom as a special feature of AS, very few studies have either defined or assessed it in a systematic manner. Therefore, the present study was undertaken to evaluate the presence of clumsiness in persons with AS, compare it to that occurring in HFA and to comment on its role as a possible diagnostic marker for this syndrome.

\section{METHOD}

The present study was conducted at the University of Michigan Medical Center. From a consecutive series of children and adolescents referred to the Developmental 
Disorders clinic, those suffering from AS and autism were identified. Diagnosis of AS was based on the ICD-10, while that of autism was based on the DSM-III-R and the ICD-10. Autistic persons with a full-scale IQ over 70, as measured by a standardized IQ test, made up the group with HFA. Patients over the age of 19 years were excluded. In accordance with the ICD-10 criteria for AS, patients with mental retardation and those with a history of language delay were also excluded. None of the AS patients met the criteria for autism. All the AS and HFA patients were Caucasian and were born in North America. None suffered from any current seizure disorder or a diagnosed medical disorder known to co-exist with autism, such as tuberous sclerosis. None of the subjects or the controls met the clinical description of fragile-X syndrome, although chromosomal analysis was not done for all patients.

Diagnosis was reached after a comprehensive evaluation which consisted of interviews with parents and other professionals, psychological evaluation, educational and occupational testing, and a detailed psychiatric examination of the patient. In addition, scales such as the Autism Behaviour Checklist (Krug et al. 1980) and the Vineland Adaptive Behaviour Scales (Sparrow et al. 1984) were also used.

For the assessment of clumsiness, the Bruininks-Oseretsky test (Bruininks 1978) was administered to both groups by a trained recreation therapist (EB), who was blind to the patients' diagnoses. The Bruininks-Oseretsky test assesses gross and fine motor functioning of children and adolescents. Normative data include standard scores for each age group, percentile ranks and stanines. Age equivalents are also provided for each of the eight subtests. Gross motor subtests include: running speed and agility; balance; bilateral coordination; upper limb coordination; and strength. Fine motor subtests consist of: response speed; visual-motor control; and upper limb speed and dexterity.

\section{RESULTS}

There were 11 patients in the AS group (10 males; mean age $13 \cdot 6 \pm 3.7$ years; full scale IQ mean, 98) and nine in the autistic group (eight males; mean age $12.9 \pm 3.8$ years; full scale IQ mean, 84). The AS group had slightly higher full scale IQ scores $P=0.0598 ; \mathrm{df}=18)$, but did not differ significantly in their verbal $(P=0.082)$ and performance $(P=0 \cdot 249)$ IQ scores. When compared with age-matched population norms given by the Bruininks-Oseretsky test (1978), problems of coordination were found in both groups. However, no significant differences were noted between AS and autistic groups so far as standard scores on the gross motor, fine motor, upper limb coordination and battery composite scores were concerned. Also, when comparisons were made between scores on the Bruininks-Oseteretsky test and the individual IQ scores of the two groups, no significant differences were found. These results are summarized below in Tables 1 and 2 .

\section{DISCUSSION}

Deficits in motor coordination were found in both the autistic and the AS groups in all the four areas of functioning, when compared with age-matched population 
Table 1. Clumsiness in Asperger syndrome and autism: a comparison of standard scores on the Bruininks-Oseretsky Test

\begin{tabular}{|c|c|c|c|c|}
\hline & $\begin{array}{l}\text { Asperger } \\
\text { syndrome }\end{array}$ & Autism & $P$ & $\begin{array}{l}\text { Population } \\
\text { norms }\end{array}$ \\
\hline Number & 11 & 9 & & \\
\hline M:F ratio & $10: 1$ & $8: 1$ & & \\
\hline Age in years (mean $\pm S D$ ) & $13 \cdot 6 \pm 3 \cdot 7$ & $12 \cdot 9 \pm 3 \cdot 8$ & & \\
\hline Full-scale IQ (mean) & 98 & 84 & 0.0598 & \\
\hline Gross motor score (mean $\pm S D)$ & $31 \cdot 3 \pm 22 \cdot 3$ & $28 \cdot 9 \pm 25 \cdot 2$ & $0 \cdot 82$ & $58 \cdot 5$ \\
\hline $\begin{array}{l}\text { Fine motor score } \\
(\text { mean } \pm S D)\end{array}$ & $25 \cdot 7 \pm 13 \cdot 9$ & $24 \cdot 9 \pm 11 \cdot 8$ & $0 \cdot 90$ & $43 \cdot 5$ \\
\hline $\begin{array}{l}\text { Upper limb coordination } \\
(\text { mean } \pm S D)\end{array}$ & $2 \cdot 8 \pm 1 \cdot 8$ & $3 \cdot 0 \pm 3 \cdot 1$ & $0 \cdot 87$ & $19 \cdot 4$ \\
\hline Battery composite $($ mean $\pm S D)$ & $59 \cdot 72 \pm 35$ & $55 \cdot 77 \pm 39$ & $0 \cdot 90$ & $113 \cdot 6$ \\
\hline
\end{tabular}

Table 2. Distribution of scores on the Bruininks-Oseretsky Test and the IQ test ${ }^{\star}$

\begin{tabular}{|c|c|c|c|c|c|c|c|c|c|c|}
\hline No. & Diagnosis & Sex & $\begin{array}{l}\text { Age } \\
\text { years }\end{array}$ & $\begin{array}{l}\text { Gross } \\
\text { motor }\end{array}$ & $\begin{array}{l}\text { Fine } \\
\text { motor }\end{array}$ & $\begin{array}{l}\text { Upper } \\
\text { limb }\end{array}$ & Battery & VIQ & PIQ & FIQ \\
\hline 1 & AS & $M$ & 17 & 33 & 14 & 1 & 48 & 105 & 91 & 91 \\
\hline 2 & AS & $M$ & 14 & 15 & 14 & 1 & 30 & 86 & 100 & 91 \\
\hline 3 & AS & $M$ & $9 \cdot 1$ & 37 & 37 & 4 & 78 & 136 & 149 & 146 \\
\hline 4 & AS & $M$ & $13 \cdot 5$ & 15 & 14 & 3 & 32 & 88 & 96 & 91 \\
\hline 5 & AS & $\mathbf{M}$ & $10 \cdot 1$ & 28 & 37 & 4 & 69 & 102 & 92 & 97 \\
\hline 6 & AS & $M$ & 15 & 17 & 16 & 2 & 35 & 74 & 76 & 82 \\
\hline 7 & AS & $\mathrm{F}$ & $13 \cdot 3$ & 21 & 34 & 2 & 57 & 114 & 114 & 116 \\
\hline 8 & AS & $M$ & $18 \cdot 9$ & 42 & 34 & 7 & 83 & 107 & 92 & 100 \\
\hline 9 & AS & $\mathbf{M}$ & $19 \cdot 6$ & 86 & 52 & 2 & 140 & 83 & 82 & 81 \\
\hline 10 & AS & $M$ & $10 \cdot 5$ & 46 & 23 & 4 & 73 & 112 & 95 & 104 \\
\hline 11 & AS & $M$ & $9 \cdot 1$ & 4 & 7 & 1 & 12 & 72 & 84 & 76 \\
\hline 12 & HFA & $M$ & $7 \cdot 4$ & 46 & 34 & 3 & 83 & 100 & 87 & 91 \\
\hline 13 & HFA & $M$ & 12 & 41 & 25 & 3 & 78 & 89 & 89 & 92 \\
\hline 14 & HFA & $M$ & $12 \cdot 1$ & 8 & 10 & 2 & 20 & 68 & 76 & 75 \\
\hline 15 & HFA & $\mathrm{F}$ & $17 \cdot 8$ & 8 & 20 & 1 & 29 & 73 & 78 & 74 \\
\hline 16 & HFA & M & $17 \cdot 9$ & 33 & 34 & 1 & 68 & 85 & 85 & 85 \\
\hline 17 & HFA & $M$ & $8 \cdot 1$ & 16 & 20 & 1 & 37 & 59 & 95 & 75 \\
\hline 18 & HFA & $M$ & $12 \cdot 1$ & 11 & 19 & 2 & 32 & 100 & 80 & 89 \\
\hline 19 & HFA & $M$ & $11 \cdot 9$ & 13 & 14 & 3 & 30 & 80 & 87 & 82 \\
\hline 20 & HFA & $M$ & $16 \cdot 9$ & 84 & 48 & 11 & 143 & 80 & 106 & 91 \\
\hline
\end{tabular}

^AS: Asperger syndrome; HFA: high-functioning autism; VIQ: Verbal IQ score; PIQ: Performance IQ score; FIQ: Full-Scale IQ.

norms (Bruininks 1978). Overall, patients with AS performed marginally better on the coordination tests than the HFA group, as reflected by the composite scores ( 59.72 vs. $57 \cdot 77 ; P=0.90$ ). No significant differences were found in any of the individual categories of gross motor, fine motor and upper limb functioning. This suggests that, despite the reported association between AS and clumsiness, this symptom may not be useful in the distinction of AS from autism on the basis of currently used tests of motor coordination. 
Before discussing the role of clumsiness in the diagnosis of AS, it is important to recognize that clumsiness itself is not an easy concept to define and measure. As Gubbay (1985) remarked, clumsiness, like immaturity, is a comparative term which is dependent on normally accepted standards. Agreement is rather low, even among professionals, as to what constitutes clumsiness (Keogh et al. 1979). Henderson \& Hall (1982) defined clumsiness as a condition in which the level of competence in motor skills is significantly below the norm, without any evidence of disease of the nervous system. Clumsy children are said to be slow in a variety of perceptual-motor tasks and have difficulties with the acquisition of such skills as writing, hopping, cycling and throwing a ball (van Dellen \& Geuze 1988).

Moreover, clumsiness is not unique to AS. Troublesome clumsiness is said to be quite common, occurring in about $2-5 \%$ of normal children, more often in boys than in girls (Gardiner-Medwin 1987). It is also reported to be common in many psychiatric disorders, such as attention deficit hyperactivity disorder and developmental expressive and receptive language disorders (APA 1987). Links have also been proposed between minor neurodevelopmental disorders such as age-related fine motor dysfunction and psychiatric disorders. For example, in a study of 141 7-year-old children in Sweden, Gillberg (1983) found that perceptual and motor deficits were associated with psychiatric symptoms, including psychotic/autistic behaviour. In fact, autistic children may also show problems with motor skills (DeMyer 1976), and tend to have problems with coordination as they reach adolescence (Wing 1981). Another issue is the presence of comorbid mental retardation. Clumsiness may be modified by the presence of mental retardation. Therefore, it is important that an allowance is made for this condition in interpreting studies on the presence of this symptom in AS and other pervasive developmental disorders.

At the same time, it is possible that a larger sample of patients may demonstrate real differences in clumsiness between the two groups, although the distribution of scores was almost identical in this study. Differences in IQ scores may also account for the failure to find differences in clumsiness between the two groups, as patients with AS had slightly higher IQ scores. Also, the fact that the AS group was marginally older should be noted, since the detection of clumsiness may be modified by age.

Even if it is accepted that both AS and HFA patients suffer from problems with coordination, it is still possible that the pattern of motor deficits may differ between the two groups. This may be of value in the differential diagnosis of these conditions. Perhaps the manner in which AS patients perform their movements is qualitatively, and not quantitatively, different from those of patients with HFA. It may well be that the 'clumsiness' that is said to be characteristic of persons with AS is more of a social nature than motoric. Another possibility is that persons with AS may appear more clumsy than they actually are because of their relatively better preserved language and cognitive skills.

In addition, it should be noted that the origins of clumsiness may lie in a variety of factors and not only in motor coordination. These factors include: information processing deficits (Smyth \& Glencross 1986); difficulties in the visual perception of distance and spatial relationships (Hulme et al. 1982); and inadequate kinesthetic sensitivity (Bairstow \& Laslo 1981). Therefore, future studies should focus on the 
determinants of clumsiness and the pattern of motor deficits that occur in persons with pervasive developmental disorders before clumsiness is accepted as a diagnostic feature of AS.

\section{REFERENCES}

American Psychiatric Association (1987) Diagnostic and Statistical Manual of Mental Disorders, Third Edition, Revised. American Psychiatric Association, Washington, DC.

Asperger H. (1944) Die autischen psychopathen im kindesalter. Archiv für Psychiatrie und Nervenkrankheiten 117, 76-137.

Bairstow P.J. \& Laszlo J.I. (1981) Kinesthetic sensitivity to passive movements and its relationship to motor development and motor control. Developmental Medicine and Child Neurology 23, 606-16.

Bruininks R. (1978) Bruininks-Oseretsky Test of Motor Proficiency American Guidance Service, Inc., Circle Pines, $M N$.

Burgoine E. \& Wing L. (1983) Identical triplets with Asperger's syndrome. British foumal of Psychiatry 143, 261-5.

DeLong R.G. \& Dwyer J.T. (1988) Correlation of family history with specific autistic subgroups: Asperger's syndrome and bipolar affective disease. Fournal of Autism and Developmental Disorders 18, 593-600.

DeMyer M. (1976) Motor, perceptual and intellectual disabilities of autistic children. In: Early Childhood Autism (ed. L. Wing) pp. 169-193. Pergamon Press, Oxford.

Gardiner-Medwin D. (1987) Developmental abnormalities of the nervous system. In: Oxford Text Book of Medicine, 2nd edn (eds D.J. Weatherwell, J.G.G. Ledingham \& D.A. Warrel) p. 21.205. Oxford University Press, Oxford.

Ghaziuddin M., Tsai L. \& Ghaziuddin N. (1992a) A comparison of the diagnostic criteria for Asperger syndrome. Fournal of Autism and Developmental Disorders 22, 643-9.

Ghaziuddin M., Tsai L. \& Ghaziuddin N. (1992b) A reappraisal of clumsiness as a diagnostic feature of Asperger syndrome. Fournal of Autism and Developmental Disorders 22, 651-6.

Ghaziuddin N., Metler M., Ghaziuddin M., Tsai L. \& Giordani B. (1993) Three siblings with Asperger syndrome: a family case study. European Child and Adolescent Psychiatry 2, 44-9.

Gillberg C. (1983) Perceptual, motor and attentional deficits in Swedish primary school children: Some child psychiatric aspects. Foumal of Child Psychology and Psychiatry 24, 377-403.

Gillberg C. (1985) Asperger's syndrome and recurrent psychosis - a case study. fournal of Autism and Developmental Disorders 15, 389-97.

Gillberg C. (1989) Asperger syndrome in 23 Swedish children. Developmental Medicine and Child Neurology 31, 520-31.

Gubbay S.S. (1975) The Clumsy Child. W.B. Saunders, Philadelphia, PA.

Gubbay S.S. (1985) Clumsiness. In: Handbook of Clinical Neurology, Vol. 2 (ed. J.A.M. Fredericks), pp. 159-67. Elsevier Science Publishers, Amsterdam.

Henderson S.E. \& Hall D. (1982) Concomitants of clumsiness in young schoolchildren. Developmental Medicine and Child Neurology 24, 448-60.

Hulme C., Biggerstaff A., Moran G. \& McKinlay I. (1982) Visual, kinesthetic and cross-modal judgments of length by normal and clumsy children. Developmental Medicine and Child Neurology 24, 461-71.

Keogh J.F., Sugden D.A., Reynard C.L. \& Calkins J.A. (1979) Identification of clumsy children: comparisons and comments. Joumal of Human Movement Studies 5, 32-41.

Krug D.A., Arick J.R. \& Almond P.J. (1980) Behaviour checklist for identifying severely handicapped individuals with high levels of autistic behavior. fournal of Child Psychology and Psychiatry 21, 221-9. 
Schopler E. (1985) Convergence of learning disabilities, higher-level autism, and Asperger syndrome. Fournal of Autism and Developmental Disorders 15, 359.

Smyth T.R. \& Glencross D.J. (1986) Information processing deficits in clumsy children. Australian fournal of Psychology 38, 13-22.

Sparrow S., Balla D. \& Cicchetti D. (1984) Vineland Adaptive Behaviour Scales. American Guidance Service, Circle Pines, MN.

Stevens D.E. \& Moffit T.E. (1988) Neuropsychological profile of an Asperger's syndrome case with exceptional calculating ability. The Clinical Neuropsychologist 2, 228-38.

Stott D., Moyes F.A. \& Henderson S.E. (1984) Manual of Test of Motor Impairment-Henderson Revision. Brook Educational, Ontario.

Szatmari P., Tuff L., Finlayson A.J. \& Bartolucci G. (1989) Asperger's syndrome and autism: neurocognitive aspects. Fournal of the American Academy of Child and Adolescent Psychiatry 29, 130-6.

Tantam D. (1988a) Asperger's syndrome: annotation. Foumal of Child Psychology and Psychiatry $29,245-55$.

Tantam D. (1988b) Lifelong eccentricity and social isolation. I. Psychiatric, social and forensic aspects. British foumal of Psychiatry 153, 777-82.

Tantam D. (1988c) Lifelong eccentricity and social isolation. II. Asperger's syndrome or Schizoid Personality Disorder. British Fournal of Psychiatry 153, 783-91.

van Dellen T. \& Geuze R.H. (1988) Motor response processing in clumsy children. fournal of Child Psychology and Psychiatry 29, 489-500.

Wechsler D. (1974) Wechsler Intelligence Scale for Children-Revised. The Psychological Corporation, New York, NY.

Wing L. (1981) Asperger's syndrome: a clinical account. Psychological Medicine 11, 115-29.

Wolff S. \& Barlow A. (1979) Schizoid Personality Disorder in childhood: a comparative study of schizoid, autistic and normal children. Fournal of Child Psychology and Psychiatry 20, 29-46.

World Health Organization (1988) The ICD-10 Classification of Mental and Behavioural Disorders (draft), WHO, Geneva.

Received 8 fanuary 1993; revised 7 fune 1993

\section{APPENDIX}

\section{ICD-10 criteria (1988) for Asperger Syndrome}

(1) A lack of any clinically significant general delay in language or cognitive development. Diagnosis requires that single words should have developed by 2 years of age or earlier, and communicative phrases by 3 years of age or earlier. Self-help skills, adaptive behaviour and curiosity about the environment during the first 3 years should be at a level consistent with normal intellectual development. However, motor milestones may be somewhat delayed and motor clumsiness is usual (although not a necessary diagnostic feature). Isolated special skills, often related to abnormal preoccupations, are common, but are not required for diagnosis.

(2) Qualitative impairments in reciprocal social interaction (criteria as for autism).

(3) Restricted, repetitive and stereotyped patterns of behaviour, interests and activities (criteria as for autism; however, it would be less usual for these to 
include either motor mannerisms, or preoccupations with part-objects or nonfunctional elements of play materials).

(4) The disorder is not attributable to the other varieties of pervasive developmental disorder; schizotypal disorder, simple schizophrenia, reactive and disinhibited attachment disorder of childhood, obsessional personality disorder, and obsessive-compulsive disorder.

\section{Case vignettes}

The following case vignettes are typical of patients diagnosed as suffering from AS or HFA.

Asperger syndrome. Matthew H., aged 15 years at the time of referral, was born after a full-term normal delivery. His motor and speech milestones were achieved at the normal time. In first grade, around 6 years of age, he was placed in a classroom for 'emotionally impaired' children because of difficulty in getting along with peers. Matthew was found to lack interest in other children and to prefer solitary activities. Because of persistent social difficulties, he was evaluated at the age of 10 years and given a diagnosis of autism. He was academically bright despite his social deficits. Matthew had no friends and his main activity outside school consisted of playing with his computer. He was fascinated with numbers and was particularly fond of the combinations of the digit ' 7 '. Matthew walked with an awkward gait and was described by his mother as being clumsy. On the Weschler Intelligence Scale for Children-Revised (Wechsler 1974), he achieved a Verbal IQ of 105, a Performance IQ of 91 and a Full-Scale IQ of 91 . On the modified Autism Behaviour Checklist (Krug et al. 1980), in which items of past behaviour were taken into consideration, Matthew was given scores of 74 by mother and 43 by father. He was given a diagnosis of AS based on the following ICD-10 criteria: lack of any clinically significant general delay in language or cognitive development; qualitative impairment in reciprocal social interaction as in autism; and a restricted pattern of interests and behaviours. In addition, Matthew did not meet the DSM-III-R or the ICD-10 criteria for autism. Details of this case are reported elsewhere (Ghaziuddin et al. 1993).

High-functioning autism. Allan R. is a 12-year-old male. He was born after a Caesarian section, following a difficult labour because of foetal distress. The pregnancy was complicated by toxaemia in the sixth month. Allan was described as a difficult infant who did not sleep or feed well. He began walking at 14 months of age and talking at 2 years, although his speech was echolalic. As a toddler, Allan was impulsive and prone to temper-tantrums. He was placed in a programme for socially and emotionally impaired children, and was diagnosed with autism at the age of 5 years. He was described as having idiosyncratic interests from the age of 4 years. Allan had always been interested in mechanical objects, particularly telephones; he collected toy telephones as well as photographs of telephones. When younger, he was preoccupied with street lights and construction equipment. Allan was also prone to be ritualistic, losing his temper whenever his routine was disturbed. He had elaborate dressing and 
bedtime rituals. His eye contact was poor and he showed a tendency to make inappropriate personal comments regarding weight, height and foot-size to people he did not know well. Allan was mildly hyperactive and had been seen by a psychiatrist in the past for this problem. In addition, he showed some stereotyped movements such as body rocking. On the modified Autism Behaviour Checklist (Krug et al. 1980), in which items of past behaviour were also taken into account, his scores were 120 (father) and 104 (mother). On the DSM-III-R (1987) and the ICD-10 (1988), the following items for the diagnosis oi autistic disorder/autism were endorsed: marked lack of awareness of the existence or feelings or others; absent or abnormal seeking of comfort at times of distress; absent or markedly abnormal social play; gross impairment in the ability to make peer friendships; markedly abnormal nonverbal communication; failure to adequately use eye-to-eye gaze and facial expression; marked abnormalities in the production of speech; marked impairment in the ability to sustain conversation; occasional stereotyped movements; and a restricted range of interests. Four behaviours from the DSM-III-R that were present in the past but not at the time of the evaluation were: absent or markedly impaired imitation; marked abnormalities in the form of speech such as echolalia; marked distress in changes in environment; and an unreasonably insistence in following routines. As the patient met the required number of criteria for the diagnosis of autistic disorder/childhood autism, the diagnosis of AS was not given. Because his Verbal IQ was 100, Performance IQ was 80 and Full-Scale IQ 89, Allan was considered to be a person with HFA. 
This document is a scanned copy of a printed document. No warranty is given about the accuracy of the copy. Users should refer to the original published version of the material. 